\title{
Organizational Virtues and Psychological Capital as Positive Predictors of Job Satisfaction and Performance
}

\author{
Rajesh Kumar Upadhyay, Namrata Prakash, Abhishek Negi
}

\begin{abstract}
In this paper we analyzed the incremental validity of the organizational virtues over the individual psychological capital (IPC) in terms of predicting performance and job satisfaction. The sample was made up of 459 Indian employees (232 men, 227 women); average age: 36.43 years $(S D=11.56)$; Belonging to public $(17.4 \%, n=80)$ and private $(82.6 \%, n=379)$ companies, the majority resided in and around Dehradun \& Haridwar city $(96.8 \%, n=443)$. For data collection, an inventory of organizational virtues -IVO, Psychological Capital Scale, and some ad-hoc designed surveys were used. Sociodemographic, organizational, job dissatisfaction, and job performance surveys. in relation to the dimensions of the IPC, regarding the prediction of satisfaction and job performance.
\end{abstract}

Keywords: Organizational Virtues, Psychological Capital, Job Satisfaction, Performance

\section{INTRODUCTION}

In this study, predictors of job satisfaction and performance are analyzed. Job satisfaction is understood as an attitude that people have towards their work (Cameron \&Spreitzer, 2012), although it has also been conceptualized as a job evaluation (Armstrong, T. J., et al., 1986).). Therefore, it involves both cognitive components - assessment and effectives. If it is intended to be analyzed, different facets must be taken into account-e.g. satisfaction with the supervisor, with coworkers, with remuneration, with the possibilities of promotion - as well as work in general (Arvey, R. D., 1986). On the other hand, job performance is related to the level of performance that a person presents in the tasks necessary for a job role and also due to their contribution to the social and psychological context of an organization (Judge, Thorensen, Bono, \& Patton, 2001). The literature on factors that predict these aspects is very extensive. However, most studies focus on classical variables. In general, the most studied predictors are linked to personality traits. For example, studies based on the Five Factor Model (FFM) - (Digman, J. M., 1990), reveal that, in general, the trait with the highest incidence on performance levels is that of responsibility (Barrick, Mount \& Judge, 2001; Salgado, 1997). and, extraversion, kindness and emotional stability are positively associated with job satisfaction (Bowling \& Burns, 2010). Various studies have also analyzed the relationship between cognitive variables and performance levels (for a review, see Schmidt \& Hunter, 1998).

Revised Manuscript Received on October 20, 2019.

Rajesh Kumar Upadhyay, Associate Professor School of Management Graphic Era Hill University Dehradun, Uttarakhand, India Email Id:upadhya.rajesh@gmail.com

Namrata Prakash, Associate Professor School of Management Graphic Era Hill University Dehradun, Uttarakhand, India Email Id:nprakash@gehu.ac.in

Dr Abhishek Negi, Associate professor, Department of management studies, Graphic Era University, Email Id:abhisheknegi.mba@geu.ac.in
Other factors commonly studied with both outcome measures are related to work environment (Amabile, T. M., \&Gryskiewicz, N. D. , 1989), burnout (Maslach, C., et al., 1986)), the characteristics of the work (eg, Hackman \& Oldham, 1975; Judge et al., 2001), among others. In this study the focus of classic variables is run and positive factors are analyzed trying test whether the perception of organizational virtues increases the effects generated by one of the variablespositive, which has proven to be one of the best predictors of optimal results, which is psychological capital (called IPC) (Luthans, F., et al., 2007)). The perspective chosen in this work is Positive Organizational Psychology (POP) (Cameron \&Spreitzer, 2012). This perspective does not represent a single theory, but rather attempts to unify a series of studies that incorporate the notion of positive. It aims to differentiate itself from classical organizational studies since they have focused only on the analysis of negative conditions and their consequences. Although the positive term has been associated with a value connotation, in recent years, it has begun to be linked to factors aimed at achieving better performance in organizations (Dutton \& Glynn, 2007). The expression psychological capital appears briefly mentioned in the economic literature of the 20th century, to refer to those facets of personality that contribute to the productivity of employees. However, it has only recently acquired relevance in the framework of Positive Organizational Psychology when it is defined by Luthans, Youssef and Avolio (2007), as the positive psychological state characterized by having the confidence to successfully carry out a challenging task -self-efficacy-, making a positive attribution on current success and future -optimism-, strengthen in adversity -resilience-, and persevere in the pursuit of goals towards success -hope- (Luthans, F., et al., 2010). Therefore, IPC is considered a higher order factor than They encompass positive psychological constructs of hope, optimism, resilience, and self-efficacy (Luthans, 2010). Luthans (2012), maintains that it is the synergistic interaction of these capacities that shapes the essence of the supra-factor IPC and explains the greater scope of its motivational effects on behavior. From this perspective, Youssef and Luthans (2012) postulated that employees who present high levels of IPC may perform better than those who only exhibit hope, optimism, resilience, or self-efficacy in a given situation. IPC dimensions are related to job performance. These results coincide with others obtained in other countries (e.g., Abbas \& Raja, 2015). On the other hand, they also found that the dimensions of IPC are associated with high levels of job satisfaction.

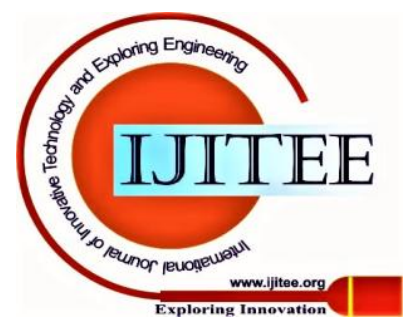




\section{Organizational Virtues and Psychological Capital as Positive Predictors of Job Satisfaction and Performance}

These findings coincide with other international research (e.g., Tang \& Tang, 2011; Li \& Ming-zheng, 2011). In particular, the most related dimensions are those of resilience, hope and optimism (Çetin, 2011).The research presented here continues a series of studies carried out in India in order to verify the effect that certain positive variables have on performance and job dissatisfaction rates. These investigations have realized the importance of considering virtues at the organizational levelsince it has been shown that the perception of such virtues by the employees of an organization favors obtaining optimal results (Cameron, Brigth, \&Caza, 2004; Cameron, et al., 2011;), hence the interest in studying whether the virtues perceived at the organizational level increase the explained variance, in relation to IPC, in terms of performance and satisfaction. Organizational virtues are defined as attributes or moral practices-eg justice, respect, dignity - globally within an organization and not as the sum of the individual virtues of its members, they would be perceived characteristics in organizations that influence the actions of people and contribute to their experiencing a fuller life, just as strengths do. individual level. Camerony Winn (2012) argue that one should speak of virtuosity -virtuosity-, instead of virtues, since they emphasize that these refer to an individual level and the expression virtuosity would refer to a collective expression. According to Cameron, BrightyCaza (2004), a global definition includes both individual actions as well as collective activities and cultural and social attributes.In addition, these virtues have two qualities: amplification -related to the fact that virtuous practical exposures would increase levels of positive emotions, social capital and prosocial behaviors, also giving feedback to these practices- and, on the other hand, the buffering quality -this quality helps to prevent negative effects, product of stressful situations, promoting a sense of resilience, solidarity and efficiency-. These qualities would favor the achievement of positive results and good performance (Bright, Cameron, \&Caza, 2006). In India, an instrument used in the research of the cited authors (Cameron et al., 2011) for the evaluation of these virtues has been adapted. The original instrument is the Positive Practices Survey that proposes to analyze six virtues: Dignity and respect, Support, Interest, Meaning, Inspiration, Forgiveness. Organizational factors regarding the dimensions of IPC lie in knowing the predictive power of variables at the organizational level above those at the individual level, an aspect that has already been extensively studied (Cameron et al., 2011). In addition, IPC is chosen as an individual level variable because it is one of the most studied positive variables in the organizational field. Lastly, recent studies have shown that positive personality factors have a greater predictive power regarding classical personality traits. This study aims to analyze the incremental validity of organizational virtues over individual psychological capital in terms of performance prediction and job satisfaction.

\section{METHOD}

\subsection{Participants}

The sample was intentional and consisted of 459 Indian adults who were active workers at the time of their evaluation. The average age was $36.43(\mathrm{SD}=11.56$, Min $=$ 20, Max $=65) .50 .5 \%(\mathrm{n}=232)$ were male and $49.5 \%(\mathrm{n}=$ 227 ) were female. Regarding their place of residence, $64.9 \%$ $(\mathrm{n}=298)$ resided in the City of Dehradun \& Haridwar, $31.9 \%(n=145)$ in Greater Dehradun \& Haridwar, 3.1\% ( $=14$ ) in some province of the state and the rest lived temporarily abroad $(n=2 ; 0.4 \%) .39 .9 \%(n=183)$ said they were married or living together, $34 \%(\mathrm{n}=156)$ were single, $18.1 \%(n=83)$ were in a relationship, $7.8 \%(n=36)$ were separated or divorced, and $0.2 \%(\mathrm{n}=1)$ be a widower. Regarding your education, $3.5 \%(n=16)$ have only primary studies, $44.2 \%(\mathrm{n}=203)$ indicated having completed secondary school, $42.9 \%(\mathrm{n}=197)$ completed tertiary university studies, and $9.4 \%(\mathrm{n}=43)$ present postgraduate studies. $69.7 \%(\mathrm{n}=320)$ self-perceived as middle class, $15.5 \%(\mathrm{n}=71)$ to the lower middle class, $13.9 \%(\mathrm{n}=64)$ to the upper middle class and $0.9 \%(\mathrm{n}=4)$ to the lower class, and $0.5 \%(\mathrm{n}=2)$ to the upper class. Regarding organizational variables, $82.6 \%(\mathrm{n}=379)$ of the employees belonged to private companies while $17.4 \%(n=80)$ worked in public sector companies. Regarding the size of the company, $41.4 \%(\mathrm{n}=190)$ belonged to large companies, $35.1 \%(\mathrm{n}=161)$ to medium-sized companies and $23.5 \%$ to small companies $(\mathrm{n}=108)$. Most of the participants had no staff in charge $(65.4 \% ; n=300)$, while $34.6 \%(n=158)$ held a leadership position.

\subsection{Construct}

\subsubsection{Organizational Virtues Inventory}

This is an Indian adaptation of the original test -Positive PracticesSurvey- (Cameron et al., 2011). This instrument is intended to evaluate virtuous practices at the organizational level. The version used in this study consists of 13 items with a five-point Likert response format, with a range from 1 (completely disagree) to 5 (totally agree). The dimensions of the test are: Support and respect -people are treated with respect and show supportive behavior and collaboration towards others-, Meaning and inspiration -the value and meaning of work is emphasized, people feel comforted and renewed by the task they carry out and They inspire each other in their work - and I'm sorry - you avoid blaming yourself and forgive mistakes. In the sample used in this study, good internal consistency indices have been obtained through Cronbach's alpha coefficient (Support and Respect $=.87$; Meaning and Inspiration $=.88 ;$ Forgiveness $=.75$ )

\subsubsection{Psychological Capital Scale}

IPC- (Omar et al., 2014): This is a 16-item test that was designed on the theoretical proposal of Luthans et ( 2019). Explanatory and confirmatory factor validity was studied, as well as reliability as internal consistency through Cronbach's alpha coefficient. The results showed the existence of four factors with satisfactory levels of validity and reliability, which were labeled as: Hope, Optimism, Resilience and Self-efficacy. In the sample used in this study, the following internal consistency indices were obtained through the Cronbach's alpha coefficient $($ Hope $=.83$; Optimism $=.88$; Resilience $=.63$; Self-efficacy $=.70$ ). In addition, a series of surveys were designed for the evaluation of some of the variables considered in the study: Organizational Survey: Consult the participants on data on the organization in which they work and the position they occupy -size, type, category, area in which they work, position and personnel in charge. Survey Job Satisfaction:

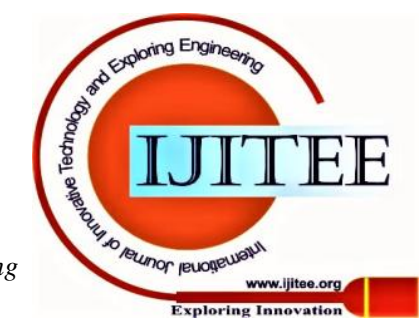


Six items were designed with a Likert response option ranging from 1 (totally dissatisfied) to 7 (totally satisfied) that attempt to assess how satisfied the person is with selfperceived in terms of their work in general and different aspects of this job, salary, bosses, companions, place, career-. An example of an item is "How satisfied am I with the salary I receive?" For the choice of the areas to be evaluated -e.g. salary, bosses, colleagues- aspects analyzed in other previous instruments were taken into account (e.g., Balzer et al., 1997). Cronbach's alpha was calculated for the total scale obtaining an acceptable value of .76.

1.2.3 Organizational and Individual Performance Survey For the design of this survey, the ones proposed by Cameron et al., (2004) in their research on positive variables and performance -i.e., efficiency, innovation, growth, quality, retention of employees and customers, satisfaction, adaptation- were taken as performance indicators. The first part of the survey consists of ten items with a Likert option of response-1 (Little) to 6 (Much) - and is aimed at evaluating organizational performance according to the perception of employees. An example of an item is "To what extent do you think the organization efficiently fulfilled - making good use of the resources - with the proposed objectives?". The alpha obtained for this section was .88. The second section, aimed at evaluating individual performance, consists of six items with the same response option as the previous section ( $1=$ Little and $6=\mathrm{A}$ lot $)$. An example of an item is: "To what extent do you think the results obtained were of quality?". The alpha obtained for this second part was .83. For the purposes of this study, only the second part was used to evaluate individual performance.

\subsection{Procedure and data analysis}

The data was collected by students who were doing a research practice at a private university in the city of Dehradun \& Haridwar. The participants were volunteers and received no compensation for their collaboration. In addition, the booklet containing the surveys featured on its cover an introduction requesting the consent of the participant, ensuring the anonymity of the data and its exclusive use for research. For data loading and analysis, the software SPPS 24.0 was used.

\section{RESULT}

First, correlation coefficients were calculated between all the analyzed variables. As detailed in Table 1, most of the correlations are significant and moderate to large effect size (Cohen, 1992). Furthermore, it is observed that the highest correlations with performance measures and job satisfaction occur with two of the organizational virtues (Support and respect; Meaning and inspiration) and with three of the variables of psychological capital (Hope, Optimism and Efficacy).

Correlation coefficients between the variables analyzed

\begin{tabular}{|c|c|c|c|c|c|c|c|c|c|c|c|}
\hline Variables & Mean & SD & 1 & 2 & 3 & 4 & 5 & 6 & 7 & 8 & 9 \\
\hline $\begin{array}{l}\text { 1. Support and } \\
\text { respect - }\end{array}$ & 3.55 & 0.7 & & & & & & & & & \\
\hline $\begin{array}{l}\text { 2. Meaning and } \\
\text { inspiration }\end{array}$ & 3.21 & 0.91 & & & & & & & & & \\
\hline 3. sorry & 3.17 & 0.83 & $.58 * *$ & $.39 * *$ & -- & & & & & & \\
\hline 4. Hope & 4.49 & 0.79 & $.37 * *$ & $.53 * *$ & $.22 * *$ & -- & & & & & \\
\hline 5. Resilience & 4.35 & 0.68 & $.16 * *$ & $.22 * *$ & 0.06 & $.58 * *$ & - & & & & \\
\hline 6. Optimism & 4.1 & 0.71 & $.43 * *$ & $.47 * *$ & $.25 * *$ & $.63 * *$ & $.48 * *$ & -- & & & \\
\hline 7. Self-efficacy & 4.55 & 0.86 & $.31 * *$ & $.43 * *$ & $.18 * *$ & $.80 * *$ & $.64 * *$ & $.64 * *$ & -- & & \\
\hline $\begin{array}{l}\text { 8. Job } \\
\text { satisfaction }\end{array}$ & 4.81 & 1.04 & $.50 * *$ & $.52 * *$ & $.28 * *$ & $.56 * *$ & $.28 * *$ & $.55 * *$ & $.45 * *$ & -- & \\
\hline $\begin{array}{l}\text { 9. Job } \\
\text { performance }\end{array}$ & 4.59 & 0.82 & $.43 * *$ & $.48 * *$ & $.16 * *$ & $.58 * *$ & $.33 * *$ & $.47 * *$ & $.50 * *$ & $.54 * *$ & -- \\
\hline
\end{tabular}

$* * \mathrm{p}<.01$

Bold correlations with moderate to large effect size.

Table 2, Multiple hierarchical regression: prediction of performance and job satisfaction $(n=459)$

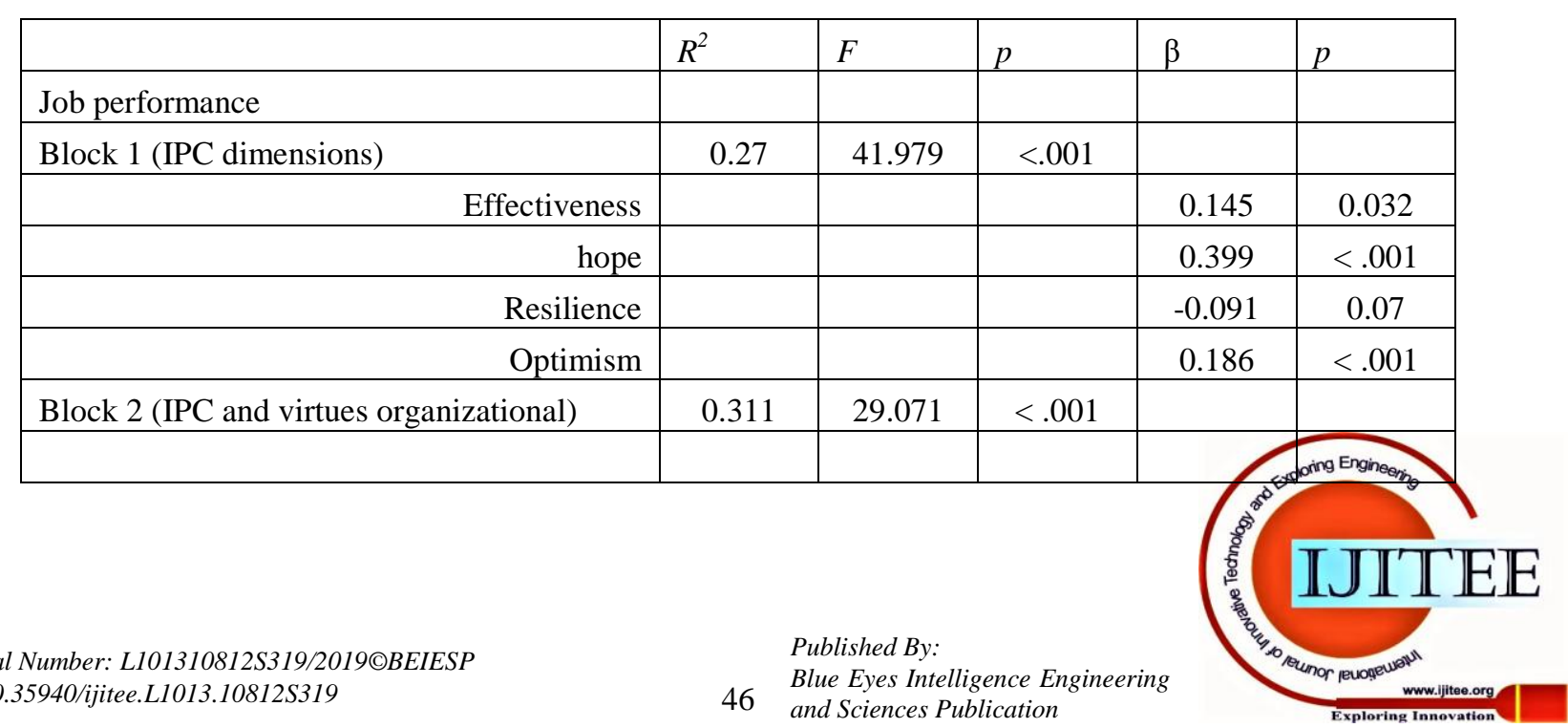


Organizational Virtues and Psychological Capital as Positive Predictors of Job Satisfaction and Performance

\begin{tabular}{|r|c|c|c|c|c|}
\hline $\mathrm{p}$ for the change of $\mathrm{F}$ & $<.001$ & & & & \\
\hline Effectiveness & & & & 0.132 & 0.047 \\
\hline hope & & & & 0.306 & $<.001$ \\
\hline Resilience & & & & -0.052 & 0.3 \\
\hline Optimism & & & & 0.138 & 0.006 \\
\hline Support and respect & & & & -0.012 & 0.822 \\
\hline Meaning and inspiration & & & & 0.234 & $<.001$ \\
\hline Pardon & & & & -0.042 & 0.324 \\
\hline
\end{tabular}

\begin{tabular}{|c|c|c|c|c|c|}
\hline & $R^{2}$ & $F$ & $p$ & $\beta$ & $p$ \\
\hline \multicolumn{6}{|l|}{ Work satisfaction } \\
\hline Block 1 (IPC dimensions) & 0.393 & 73.624 & $<.001$ & & \\
\hline Effectiveness & & & & 0.037 & 0.579 \\
\hline hope & & & & 0.402 & $<.001$ \\
\hline Resilience & & & & -0.147 & 0.003 \\
\hline Optimism & & & & 0.348 & $<.001$ \\
\hline Block 2 (IPC and virtues organizational) & 0.46 & 54.933 & $<.001$ & & \\
\hline$p$ for the change of $F$ & $<.001$ & & & & \\
\hline Effectiveness & & & & 0.011 & 0.864 \\
\hline hope & & & & 0.294 & $<.001$ \\
\hline Resilience & & & & -0.8 & 0.094 \\
\hline Optimism & & & & 0.235 & $<.001$ \\
\hline Support and respect & & & & 0.216 & $<.001$ \\
\hline Meaning and inspiration & & & & 0.161 & $<.001$ \\
\hline Pardon & & & & -0.028 & 0.522 \\
\hline
\end{tabular}

Some posteriori, a multiple hierarchical regression analysis was calculated to study whether the perception of organizational virtues increases the prediction of the performance and job satisfaction of the workers, beyond the variance explained by the dimensions of the IPC at the individual level. Firstly, the dimensions of IPC were introduced as predictors of the first block and then the dimensions of organizational virtues in the second block. In both cases the models were statistically significant $(\mathrm{p}<.001)$ and the organizational virtues significantly increased the change in R2 (see Table 2). In all cases, the multicollinearity tests showed acceptable values, with the tolerance values of the variables close to 1.00 . In addition, the Durbin-Watson statistic was used in order to evaluate the absence of correlation of the residuals presenting values close to 2.00 (Pardo \& Ruiz, 2005). As for the labor performance, the R2 of Block 1 was .270 ( $\mathrm{p}<.001)$. All the dimensions of IPC, with the exception of resilience, were statistically significant predictors. In Block 2, R2 became .311 ( $\mathrm{p}<.001$ ), so the inclusion of the organizational virtues added $4.1 \%$ of variance. IPC maintained its statistical significance as predictors of performance. In relation to the virtues, meaning and inspiration, it turned out to be the greatest predictive power $(=.234, \mathrm{p}<.001)$. (See Table 2$)$.On the other hand, regarding job satisfaction, the R2 of Block 1 was. 393 ( $p<.001)$. All the dimensions of the IPC, with the exception of efficacy, were statistically significant predictors. The change in $\mathrm{R} 2$ when calculating Block 2 was statistically significant ( $\mathrm{p}<.001)$ and R2 was .460 ( $<<.001)$, for which it provided $6.7 \%$ of variance. In this block, hope $(\beta=.294, \mathrm{p}<.001)$ and optimism $(\beta=.235, \mathrm{p}<.001)$ remained significant predictors. In relation to organizational strengths, support and respect $(\beta=.216, \mathrm{p}<.001)$, and meaning and inspiration $(\beta=.161, \mathrm{p}<.001)$ they turned out to be statistically significant predictors (See Table 2). It is observed that, for both performance and job satisfaction, the inclusion of organizational strengths increases the percentages of explained variance considering the model that includes only the dimensions of IPC. On the other hand, the virtue of forgiveness and the resilience dimension of IPC do not contribute significantly to obtaining optimal results in terms of performance as well as experimentation with job dissatisfaction. These results complement the information analyzed in Table 1 since, although the correlation coefficients found were significant, the effect size is small.

\section{DISCUSSION}

In this incremental validity study, we sought to identify whether the perceived virtues at the organizational level increase the variance explained, in relation to the IPC, in the prediction of job satisfaction and performance in a sample of Indian employees.

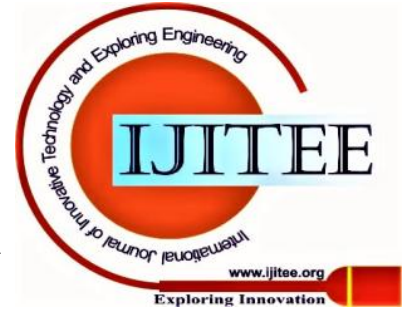


The results obtained confirm that the model that incorporates the organizational virtues significantly increases the explained variance compared to the one that only includes the dimensions of the IPC. In any case, the effect is greater with respect to satisfaction than performance. These results are consistent with previous research (egTang \& Tang, 2011) that have shown that the virtues correlate more strongly with measures of satisfaction than result. The value and positive connotation at the organizational level that the virtues present would seem to be a factor that increases the perception of feeling satisfied with the work, over the dimensions of the IPC. The analysis of the individual predictors included in the Block 2 model of job satisfaction indicates that the resilience dimension of CAPSSI loses its predictive power in this block. The positive predictors of this block are: hope and optimism of the IPC and the organizational virtues support and respect and, meaning and inspiration. Regarding performance, the analysis of the individual predictors included in block 2 shows that all the dimensions of the IPC -except for resilience - and virtue meaning and inspiration are positive predictors of job performance. It should be noted that although having confidence to successfully carry out a task effectiveness- is important in predicting performance, the other predictors are more significant. Therefore, being optimistic about current and future success - optimism being persevering - hope - and feeling that the work done meaning and inspiration - is given more significant contribution to obtaining good results. The results obtained are consistent both with previous research on IPC (eg, Abbas \& Raja, 2015; Badran, 2015; Omar et al., 2014; Cheung, among others) as of virtues (eg Cameron et al., 2004; Cameron et al., 2011 among others).However, in the analyzed sample it was not demonstrated that resilience was a predictor of the variables analyzed here, data that is not in tune with some studies carried out in other countries (eg, Çetin, 2011). It can be highlighted as strengths of the study carried out the joint analysis of variables at the individual and organizational level, as well as the he impulse to the development at a Latin American level of organizational studies based on a positive orientation, a situation that has been growing in recent years. In addition, the results obtained consider the idiosyncrasy and local needs. As for possible limitations, the use of subjective measures to estimate work performance can be mentioned. Likewise, the sample used is somewhat unbalanced in terms of the percentage of public and private companies included.In future studies it would be convenient to use objective performance measures in order to give more credit to the predictions made in terms of efficiency. It would also be interesting to analyze these aspects taking into account some variables. . For example, the predominant type of organizational culture since it may have some influence on the results obtained.

\section{REFERENCE}

1. Abbas, M. \& Raja, U. (2015). Impact ofPsychological Capital on InnovativePerformance and Job Stress.Canadian Journal of AdministrativeSciences, $\quad 32(2), \quad 128-138$. https://doi.org/10.1002/cjas.1314

2. Amabile, T. M., \&Gryskiewicz, N. D. (1989). The creative environment scales: Work environment inventory. Creativity research journal, 2(4), 231-253.
3. Armstrong, T. J., Radwin, R. G., Hansen, D. J., \& Kennedy, K. W. (1986). Repetitive trauma disorders: job evaluation and design. Human factors, 28(3), 325-336.

4. Arvey, R. D. (1986). Sex bias in job evaluation procedures. Personnel Psychology, 39(2), 315-335.

5. Avey, J. B., Nimnicht, J., \& Graber, N.(2010). Two field studies examiningthe association between psychologicalcapital and employee performance.Leadership\&OrganizationDevelopment Journal, 31(5), 384-401.https://doi.org/10.1002/hrdq.20070

6. Avey, J. B., Reichard, R. J., Luthans, F. \&Mhatre, K. H. (2011). Meta-analysisof the impact of psychological capitalon employee attitudes, behaviors, and performance. Human ResourceDevelopment Quarterly, 22(2),127-152. https://doi.org/10.1002/hrdq.20070

7. Badran, M.A. \& Youssef-Morgan, C.M.(2015). Psychological capital andjob satisfaction in Egypt. Journal ofManagerial Psychology, 30 (3), 354-370, https://doi.org/10.1108/JMP-06-2013-0176

8. Balzer, W. K., Kihm, J. A., Smith, P. C.,Irwin, J. L., Bachiochi, P. D., Robie,C.,... Parra, L. F. (1997). User'smanual for the Job Descriptive Index(JDI; 1997 Revision) and the Job inGeneral (JIG) Scales. Bowling Green,OH: Bowling Green State University.

9. Barrick, M. R., Mount, M. K., \& Judge, T. A.(2001). Personality and Performanceat the Beginning of the NewMillennium: What Do We Know andWhere Do We Go Next? InternationalJournal of Selection and Assessment,9, 9-30. https://doi.org/10.1111/1468-2389.00160

10. Bowling, N. A. \& Burns, G. N. (2010).A comparison of work-specific andgeneral personality measures aspredictors of work and nonworkcriteria. Personality and IndividualDifferences, 49, 95-101. https://doi.org/10.1016/j.paid.2010.03.009

11. Bright, D. S., Cameron, K. S., \&Caza, A.(2006). The Amplifying and BufferingEffects of Virtuousness in DownsizedOrganizations. Journal of BusinessEthics, 64, 249-269. https://doi.org/10.1007/s10551-005-5904-4

12. Cameron, K. S., Bright, D., \&Caza, A. (2004).Exploring the relationship betweenorganizationalvirtuosnessandperformance. American BehavioralScientist, $\quad 47, \quad 1-24$ http://dx.doi.org/10.1177/0002764203260209

13. Cameron, K.S. \& Winn, B. (2012). Virtuousness in Organizations. In: K.S. Cameron \& G. M. Spreitzer (Eds.), The Oxford Handbook of PositiveOrganizational Scholarship (pp. 231-243). New York: Oxford UniversityPress

14. Cameron, K.S., \&Spreitzer, G.M. (2012).What is positive about PositiveOrganizational Scholarship? In: K. S.Cameron\& G. M Spreitzer (Eds.),The Oxford Handbook of PositiveOrganizational Scholarship (pp.1-14). New York: Oxford UniversityVirtudesorganizacionales $\quad$ y $\quad$ Capital psicológicocomopredictorespositivos de... 33Revista de Psicología. Año 2019. Vol. 15, No 29, pp. 22-35Press.

15. Cameron, K.S., Mora, C., Leutscher,T., \&Calarco, M. (2011).Effects of positive practices onorganizational effectiveness. TheJournal of applied BehavioralScience, 47, 266-308. https://doi.org/10.1177/0021886310395514

16. Çetin, F. (2011). The effects of theorganizational psychological capitalon the attitudes of commitment andsatisfaction: A public sample inTurkey. European Journal of SocialSciences, 2(3), 373-380.

17. Cheung, F., Tang, C. \& Tang, S. (2011).Psychological capital as a moderatorbetween emotional labor and jobsatisfaction among school teachers inChina. International Journal of StressManagement, 18(4), 348-371. https://doi.org/10.1037/a0025787

18. Cohen, J. (1992). A power primer.Psychological Bulletin,112(1), 155 159. https://10.1037/0033-2909.112.1.155Costa, P. T. \& McCrae, R. R. (1985).The NEO Personality InventoryManual. Odessa, FL: PsychologicalAssessment Resources.

19. de la Iglesia, G., LupanoPerugini, M.L.,\& Castro Solano, A. (2018) PositivePersonality

suasociaciónalfuncionamientoóptimoentrabajadoresactivos. PUCP. Enprensa

20. Digman, J. M. (1990). Personality structure: Emergence of the fivefactor model. Annual review of psychology, 41(1), 417-440.

21. Dutton, J.E., \& Glynn, M. (2007). PositiveOrganizational Scholarship. In: C.Cooper\& J. Barling (Eds.), Handbookof organizational behavior. ThousandOaks, CA: Sage.

22. Fineman, S. (2006). On being positive:Concerns and counterpoints Academyof Management Review, 31, 270-291. http://dx.doi.org/10.5465/AMR.2006.20208680

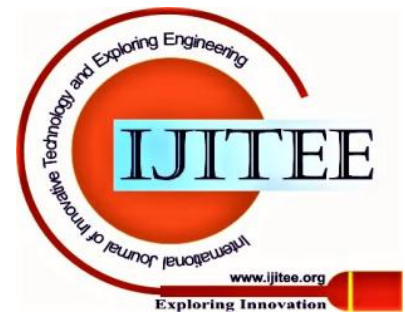


23. Hackman, J. R. \& Oldham, G. R. (1975).Development of the Job DiagnosticSurvey. Journal of AppliedPsychology, 60(2),159-170

24. Haynes, S. N., \&Lench, H. C. (2003).Incremental Validity of New ClinicalAssessment Measures. PsychologicalAssessment, 15(4), 456466.http://dx.doi.org/10.1037/1040-3590.15.4.456

25. Hunsley, J., Meyer, G.J. (2003). Theincremental validity of psychologicaltesting and assessment: conceptual,methodological, and

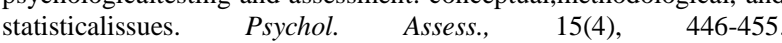
https://doi.org/10.1037/1040-3590.15.4.446

26. Judge, T. A., Thorensen, C.J., Bono,J.E., \& Patton, G.K. (2001). Thejob satisfaction-job performancerelationship: A qualitative andquantitative review. Psychological Bulletin, 127, 376-407.

27. King, G., Pan, J., \& Roberts, M. E. (2013). How censorship in China allows government criticism but silences collective expression. American Political Science Review, 326-343.

28. Li, Z. \& Ming-zheng, Z. (2011). Therelationship between psychologicalcapital and job satisfaction, lifesatisfaction: mediator role of workfamilyfacilitation. Chinese Journal of Clinical Psychology, 19(6), 818-820.

29. Luthans, F., Avey, J. B., Avolio, B. J., \& Peterson, S. J. (2010). The development and resulting performance impact of positive psychological capital. Human resource development quarterly, 21(1), 41-67.

30. Luthans, F., Youssef, C. M., \&Avolio, B. J. (2007). Psychological capital: Developing the human competitive edge.

31. Maslach, C. Jackson, S. E., Leiter, M. P., Schaufeli, W. B., \& Schwab, R. L. (1986). Maslach burnout inventory (Vol. 21, pp. 34633464). Palo Alto, CA: Consulting psychologists press. 